\title{
Clinical utility and long-term use of atazanavir in the treatment of HIV-I infection
}

\author{
This article was published in the following Dove Press journal: \\ Virus Adaptation and Treatment \\ 24 March 20II \\ Number of times this article has been viewed
}

\author{
Thomas Rampling \\ Mark Nelson \\ Chelsea and Westminster Hospital \\ NHS Foundation Trust, London, UK
}

Correspondence: Thomas Rampling Chelsea and Westminster Hospital NHS Foundation Trust, 369 Fulham Road, London SWIO 9NH, UK

Email tommy rampling@hotmail.com

\begin{abstract}
The protease inhibitor atazanavir (ATV) now forms an integral component of many combination antiretroviral regimens. It has been shown to have a favorable side effect profile, and it does not negatively affect plasma lipids as some other protease inhibitors can. ATV also has a long half-life, which allows for a once-daily dosing schedule. Coadministration of ATV with low-dose ritonavir (RTV) potentiates the effect of ATV ("RTV boosting"), allowing for lower doses of ATV than those prescribed without RTV. ATV boosted with RTV (ATV/r) has shown noninferiority to RTV-boosted lopinavir (LPV/r), and it has been shown to be effective as a simplification strategy in switch studies. ATV/r-based regimens have also shown promise as a rescue strategy for patients failing other regimens. Several important adverse events and drug interactions have been identified, and care must be taken when administering ATV with other medications. The most commonly reported adverse effect is unconjugated hyperbilirubinemia, which occurs as a result of the metabolic pathway by which it is excreted. Resistance to ATV has been described in both treatment-experienced and treatment-naïve patients.
\end{abstract}

Keywords: atazanavir, HIV, protease inhibitors, drug resistance

\section{Introduction to HIV-I management: choice of agent and resistance issues}

The natural history of human immunodeficiency virus-1 (HIV-1) infection has changed significantly since the incorporation of protease inhibitors (PIs) into nucleoside-based triple drug regimens in the mid-1990s. Although the early PIs showed promise with regard to viral suppression and immune reconstitution, other issues, such as high pill burden, poor side effect profile, metabolic disturbance, and frequent dosing schedule, cast doubt on their practical utility. The PI atazanavir (ATV) received US Food and Drug Adminsitration approval for the treatment of HIV infection in 2003. ${ }^{1}$ Since then, it has been shown to be safe, tolerable, and effective as a component of highly active antiretroviral treatment (HAART) regimens in several patient groups while retaining the advantages of simple dosing schedules. In this review we assess the evidence supporting the efficacy, safety, and tolerability of this drug and look at the role of this drug in the developing complex areas of HIV therapy, such as simplification and salvage strategies.

\section{Review of pharmacology}

ATV is an azapeptide inhibitor of HIV-1 protease and prevents the formation of mature virions in HIV-1-infected cells. It inhibits the cleavage of gag and gag-pol polyproteins of HIV-1 group M subtypes A, B, C, D, AE, AG, F, G, and J in infected cells. ${ }^{1}$ 
ATV is only available as an oral preparation. It is rapidly absorbed and reaches peak serum concentrations 2.5 hours after dosing. A steady state is reached between 4 days and 8 days, and it has nonlinear pharmacokinetics and clearance, which allow for once-daily (od) dosing. ${ }^{2}$ Administration of ATV with food enhances bioavailability and reduces pharmacokinetic variability. In the presence of a light meal, the exposure measured as area under the curve (AUC) was increased by $70 \%$, with a $57 \%$ increase in maximum observed plasma concentration $\left(C_{\max }\right)$ compared with the fasting state. Drugs that increase gastric $\mathrm{pH}$, such as proton pump inhibitors (PPIs) and H2-receptor antagonists (H2RAs), significantly reduce the absorption of ATV, and coadministration should be avoided if possible. For similar reasons, didanosine (DDI)buffered tablets should be dosed at least 1 hours before or 2 hours after ATV and on an empty stomach. ${ }^{2}$

ATV is extensively metabolized by the liver, via the cytochrome P450 family 3, subfamily A (CYP3A) enzyme pathway. ${ }^{2}$ The CYP3A locus includes all the known members of the 3A subfamily of the cytochrome P450 superfamily of genes (CYP3A4, CYP3A5, CYP3A7, and CYP3A43). CYP3A is affected by many other commonly prescribed drugs and is also an important enzyme in the metabolism of many medications. UDP-glucuronosyltransferase 1-1 (UGT1A1) is an enzyme of the glucuronidation pathway and is required for conjugation of bilirubin. ATV inhibits UGT1A1, and by this mechanism can cause hyperbilirubinemia. The inhibitory action of ATV on these two enzyme pathways is an important consideration for potential drug interactions. ATP-binding cassette subfamily B member 1 (ABCB1) is a glycoprotein that is a well-characterized ABC transporter of the MDR/ TAP subfamily. It is extensively distributed and expressed in the intestinal epithelium, hepatocytes, renal proximal tubular cells, adrenal gland, and capillary endothelial cells comprising the blood-brain and blood-testis barrier. Polymorphisms in CYP3A5, ABCB1, and UGT1A1 are associated with ATV pharmacokinetics and pharmacodynamics in vivo. ${ }^{3}$ Patients who express CYP3A5 had faster ATV clearance and lower $C_{\text {min }}$ than nonexpressors. The effect was most pronounced in non-African-American men. The addition of ritonavir (RTV) lessens CYP3A5 expressor effects. The wild-type ABCB1 CGC haplotype was associated with slower clearance, and the UGT1A1 *28 genotype was associated with more severe (grade 3-4) hyperbilirubinemia.

Approximately $27 \%$ of unchanged ATV is eliminated in the feces and urine. The elimination profile of ATV does allow for od dosing. There are few data on the use of ATV in patients with renal failure, but as it is extensively metabolized in the liver, it is unlikely that ATV would require dosage adjustment in patients with renal insufficiency.

A high-performance liquid chromatography method that is efficient has been described, which has the necessary accuracy and precision for the rapid quantitative determination of ATV in human plasma. This has potential implications for therapeutic drug monitoring and further studies. ${ }^{4}$

Concentrations of ATV in cerebrospinal fluid (CSF) are very variable. Even with RTV boosting, CSF concentrations are $\sim 100$-fold lower than those in the serum, and they do not consistently exceed the wild-type IC50 of ATV. ${ }^{5}$ Thus, ATV may not protect against viral replication in the CSF.

\section{Drug interactions}

A good drug interaction profile is integral to the success of an ARV agent, as combination therapy remains the mainstay of treatment. Coadministration of ATV with certain drugs such as indinavir (IDV) and the cancer chemotherapy drug irinotecan is contraindicated because they are metabolized by CYP3A and increase the risk of additive hyperbilirubinemia. Many additional drugs, including ARV agents, require dosage adjustment. Certain interactions, eg, those occurring between ATV and tenofovir (TFV), can be partially overcome through the addition of RTV. ${ }^{6}$

Previous studies have indicated that coadministration of ATV with gastric acid-reducing agents such as protein pump inhibitors (PPIs) and H2RAs significantly decreases ATV exposure. One study compared the effects of omeprazole and ranitidine on the pharmacokinetics of lopinavir/RTV (LPV/r) and ATV/r. ${ }^{7}$ Their results indicated that LPV bioavailability was not affected by the coadministration of RTV and either omeprazole or ranitidine. In contrast, ATV bioavailability was decreased by $48 \%-62 \%$ when coadministered with RTV and either omeprazole or ranitidine. It has recently been shown, however, that omeprazole $20 \mathrm{mg}$ od coadministered with an increased ATV/r dose (400/100 compared with the conventional 300/100) had significantly less profound effects on ATV pharmacokinetics. ${ }^{8}$ The AUC and $C_{\min }$ achieved were comparable with or greater than those achieved without omeprazole. The effect of omeprazole on this dose was also shown to be similar when given $1 \mathrm{~h}$ prior to ATV or when separated by 12 hours.

The antifungal posaconazole increases $C_{\max }$ and AUC of ATV by 2.6- and 3.7-fold, respectively. ${ }^{9}$ When boosted with RTV, the ATV $C_{\max }$ and AUC are increased by 1.5- and 2.5fold, respectively, when posaconazole is given. Most subjects who received ATV (with and without RTV) and posaconazole experienced clinically relevant increases in total bilirubin. 
This has implications for the HIV patient group, who, depending on their stage of disease or other factors, such as malignancy, may be more at risk of invasive fungal disease than non-HIV-infected individuals.

As previously described, boosting with low-dose RTV increases the plasma concentrations of ATV. This drug interaction can be harnessed for benefit and appears to be a superior strategy for treatment-experienced and treatment-naïve patients, compared with ATV alone. ATV (300 mg od) + RTV (100 mg od) results in a maximum concentration of ATV comparable with that obtained when using $600 \mathrm{mg}$ of ATV alone. ${ }^{10}$ Coadministration of ATV and TFV is currently not recommended without RTV. This is because plasma concentrations of ATV are substantially reduced in combination with TFV. Surprisingly, no real difference in virological outcomes emerged between the two groups when TFV was present in the backbone therapy with other nucleoside reverse transcriptase inhibitors (NRTIs). ${ }^{11}$

Table 1 is adapted from the Reyataz full prescribing information ${ }^{12}$ and summarizes established, potentially significant, ATV drug interactions.

\section{Resistance}

ATV has been shown to have a similar protein bindingadjusted inhibitory quotient (IQ) to those measured for LPV and darunavir (DRV) used once daily in first-line treatment. ${ }^{13}$ The selection of resistance in the case of virological failure (plasma viral load $>400 \mathrm{HIV}-1$ RNA copies/mL) to ATV/r used in first-line therapy seems uncommon, as it is for other boosted PIs. ${ }^{13}$

Resistance patterns to ATV vary according to the antiviral history of the individual and trends within prescribers. A single mutation within the protease gene can confer resistance to ATV, but generally ATV resistance occurs when several mutations are present.

In patients who have not previously been exposed to PIs, the most frequent mutation in patients failing an ATV-containing regimen is an isoleucine-to-leucine substitution at residue 50 (I50L). This is the signature resistance mutation for ATV. ${ }^{14}$ Although this mutation conferred resistance to ATV, it increased susceptibility to other PIs. ${ }^{15}$ The prevalence of I50L in large HIV drug resistance mutation databases is generally very low. ${ }^{16}$ In patients with a prior history of PI use, the mutations I84V and N88S are more commonly selected. There appears to be no obvious cross-resistance pattern of ATV with any other PI. However, cross-resistance with ATV is seen in isolates resistant to four or more PIs. ${ }^{17}$

\section{Efficacy studies}

\section{ATV in ARV-naïve patients}

ATV has been compared with other PIs and nonnucleoside reverse transcriptase inhibitors (NNRTIs) as part of triple therapy with two NRTIs in treatment-naïve patients.

Two early studies compared different doses of unboosted ATV with nelfinavir (NFV) along with DDI/stavudine (D4T) or lamivudine (3TC)/D4T and found a similar virological response to both PIs in terms of mean viral load reduction at 48 weeks and an increase in $\mathrm{CD}^{+}$lymphocytes. ${ }^{18,19}$ ATV was well tolerated, and the best efficacy/safety profile was found when ATV was given at $400 \mathrm{mg}$ od. The most striking advantage over NFV was the dramatically reduced rates of hypercholesterolemia and hypertriglyceridemia in the ATV group compared with NFV. Patients who switched from NFV to ATV showed a significant mean percentage decrease in total cholesterol $(-16 \%)$, fasting low-density lipoprotein cholesterol (LDL) (-21\%), and fasting triglycerides (-28\%) $(P<0.0001)$ by week 12 of ATV treatment.

When combined with zidovudine (AZT)/3TC, ${ }^{20}$ unboosted ATV and efavirenz (EFV) showed comparable performance of $70 \%$ and $64 \%$, respectively, attaining $<400$ HIV-RNA copies/mL after 48 weeks. Similar rates of $\mathrm{CD}^{+}$ cell gains were also observed. The mean increase in total cholesterol and LDL was significantly higher for EFV than for ATV $(+21 \%$ and $+18 \%$ vs $+2 \%$ and $+1 \%$, respectively). Mean triglyceride levels decreased with ATV (-9\%) and increased with EFV (+23\%).

RTV boosting of ATV in an HAART regimen enhances the concentrations of ATV and improves virological activity compared with unboosted ATV. Efficacy and safety of boosted versus unboosted ATV in a HAART regimen have been demonstrated in two 96-week studies. ${ }^{21,22}$ Adverse event-related discontinuations were higher in the boosted arm than those in the unboosted arm in both studies ( $8 \%$ vs $3 \%$, respectively; $8 \%$ vs $<1 \%$, respectively). In these studies, the results suggest that the rate of response may be higher and the emergence of PI resistance may be lower in subjects on $\mathrm{ATV} / \mathrm{r}$ than in those on unboosted ATV, but these results were not shown to be statistically significant.

Unboosted ATV is given once daily and has fewer adverse effects on lipid profiles than other available PIs. Unboosted ATV is not a recommended PI in ARV-naïve patients but may be considered as initial therapy for some patients in certain circumstances in which patients are not candidates for NNRTI-based regimens and in whom hyperlipidemia may be particularly undesirable. ${ }^{23}$ Unboosted ATV should not be used if TFV or EFV is being used concomitantly, 
Table I Established potentially significant drug interactions with atazanavir (ATV)

\begin{tabular}{|c|c|c|}
\hline $\begin{array}{l}\text { Concomitant } \\
\text { drug class }\end{array}$ & $\begin{array}{l}\text { Effect of concentration on } \\
\text { ATV or concomitant drug }\end{array}$ & Clinical comment \\
\hline NRTIs & & Give ATV $2 \mathrm{~h}$ before or I $\mathrm{h}$ after buffered DDI tablets. \\
\hline Didanosine (DDI) & $\begin{array}{l}\downarrow \text { ATV } \\
\downarrow D D I\end{array}$ & $\begin{array}{l}\text { ATV and enteric coated DDI capsules should be administered } \\
\text { at different times. }\end{array}$ \\
\hline Tenofovir (TFV) & $\begin{array}{l}\downarrow A T V \\
\uparrow T F V\end{array}$ & $\begin{array}{l}\text { ATV and TFV should not be coadministered } \\
\text { without RTV boosting. }\end{array}$ \\
\hline $\begin{array}{l}\text { NNRTIs } \\
\text { Efavirenz (EFV) } \\
\text { Nevirapine (NVP) }\end{array}$ & $\begin{array}{l}\downarrow A T V \\
\downarrow A T V \\
\uparrow N V P\end{array}$ & $\begin{array}{l}\text { Should not be coadministered in treatment-experienced } \\
\text { patients. In treatment-naïve patients, ATV } 400 \mathrm{mg} \text { od } \\
\text { should be given with RTV } 100 \mathrm{mg} \text { od and EFV } 600 \mathrm{mg} \text { od. } \\
\text { ATV and NVP should not be coadministered. }\end{array}$ \\
\hline Pls & & Although not studied, the coadministration of ATV/r \\
\hline $\begin{array}{l}\text { Saquinavir (SQV) } \\
\text { Ritonavir (RTV) }\end{array}$ & $\begin{array}{l}\uparrow S Q V \\
\uparrow A T V\end{array}$ & $\begin{array}{l}\text { and other Pls would be expected to increase } \\
\text { exposure to the other PI. Such coadministration }\end{array}$ \\
\hline Other Pls & Other Pls & is not recommended. \\
\hline $\begin{array}{l}\text { Antacids and buffered } \\
\text { medications }\end{array}$ & $\downarrow$ Atazanavir & $\begin{array}{l}\text { Administer ATV } 2 \mathrm{~h} \text { before or I } \mathrm{h} \text { after } \\
\text { these medications. }\end{array}$ \\
\hline Antiarrhythmics & $\begin{array}{l}\uparrow \text { Amiodarone, bepridil, } \\
\text { lidocaine, quinidine }\end{array}$ & $\begin{array}{l}\text { Effects not studied but potential for life-threatening interaction. } \\
\text { Caution advised and ECG/drug monitoring recommended. }\end{array}$ \\
\hline $\begin{array}{l}\text { Anticoagulants } \\
\text { Antidepressants }\end{array}$ & 个Warfarin & Bleeding risk. Careful INR monitoring. \\
\hline Tricyclic antidepressants & 个Tricyclic antidepressants & $\begin{array}{l}\text { Effects not studied but potential for life-threatening interaction. } \\
\text { Caution advised and drug monitoring recommended. }\end{array}$ \\
\hline Trazodone & 个Trazodone & Caution advised. Lower dose of trazodone recommended. \\
\hline Antigout & $\uparrow$ Colchicine & $\begin{array}{l}\text { Adjusted regimen recommended. Refer to } \\
\text { ATV prescribing information. }\end{array}$ \\
\hline Antimycobacterials & $\uparrow$ Rifabutin & $\begin{array}{l}\text { Reduce dose of rifabutin by up to } 75 \% \text {. Monitor for } \\
\text { adverse effects of rifabutin. }\end{array}$ \\
\hline Benzodiazepines & $\uparrow$ Midazolam & $\begin{array}{l}\text { Coadministration with parenteral midazolam is contraindicated. } \\
\text { Caution and dose reduction advised for coadministration with } \\
\text { parenteral midazolam. }\end{array}$ \\
\hline $\begin{array}{l}\text { Calcium channel blockers } \\
\text { Diltiazem } \\
\text { Felodipine, nifedipine, } \\
\text { nicardipine, verapamil }\end{array}$ & $\begin{array}{l}\text { TDiltiazem } \\
\text { } F \text { Felodipine, nifedipine, } \\
\text { nicardipine, verapamil }\end{array}$ & $\begin{array}{l}\text { Effects not studied. Consider dose reduction of diltiazem } \\
\text { by } 50 \% \text { and dose titration of other calcium channel } \\
\text { blockers. ECG monitoring recommended and } \\
\text { caution advised. }\end{array}$ \\
\hline $\begin{array}{l}\text { Endothelin receptor } \\
\text { antagonists: bosentan }\end{array}$ & $\begin{array}{l}\downarrow \text { Atazanavir } \\
\uparrow \text { Bosentan }\end{array}$ & $\begin{array}{l}\text { Coadministration of ATV with bosentan without RTV boosting } \\
\text { is not recommended. Patients must have been established on } \\
\text { ATV for at least } 10 \text { days before starting bosentan. If already } \\
\text { receiving bosentan and due to start ATV, bosentan must be } \\
\text { held for at least } 36 \text { h before starting ATV and resumed at } \\
\text { least } 10 \text { days after starting ATV. }\end{array}$ \\
\hline $\begin{array}{l}\text { HMG-CoA reductase } \\
\text { inhibitors }\end{array}$ & $\uparrow$ Atorvastatin, rosuvastatin & $\begin{array}{l}\text { Use the lowest possible dose of atorvastatin } \\
\text { or rosuvastatin with careful monitoring or consider } \\
\text { other HMG-CoA reductase inhibitors. }\end{array}$ \\
\hline $\begin{array}{l}\text { H2-receptor } \\
\text { antagonists (H2RAs) }\end{array}$ & $\downarrow$ Atazanavir & $\begin{array}{l}\text { ATV } 300 \mathrm{mg} \text { with RTV } 100 \mathrm{mg} \text { od with food should be } \\
\text { administered simultaneously with, and/or at least } 10 \mathrm{~h} \text { after, a dose } \\
\text { of the H2RA. If given with tenofovir and H2RAs, ATV } 400 \mathrm{mg} \text { and } \\
\text { RTV } 100 \mathrm{mg} \text { od should be given. For patients unable to tolerate } \\
\text { RTV, ATV } 400 \mathrm{mg} \text { od with food should be administered at least } \\
2 \mathrm{~h} \text { before and at least } 10 \mathrm{~h} \text { after a dose of the H2RA. }\end{array}$ \\
\hline $\begin{array}{l}\text { Combined hormonal } \\
\text { contraceptives }\end{array}$ & & $\begin{array}{l}\text { Caution advised. If coadministered without RTV, the } \\
\text { contraceptive pill should contain at least } 35 \mu \mathrm{g} \text { of }\end{array}$ \\
\hline Ethinyl estradiol with & $\downarrow$ Ethinyl estradiol & ethinyl setradiol. If administered without RTV, the \\
\hline norgestimate & $\uparrow$ Norgestimate & oral contraceptive should contain no more than \\
\hline $\begin{array}{l}\text { Ethinyl estradiol } \\
\text { with norethindrone }\end{array}$ & $\begin{array}{l}\uparrow \text { Ethinyl estradiol } \\
\uparrow \text { Norethindrone }\end{array}$ & $30 \mu \mathrm{g}$ of ethinyl estradiol. \\
\hline
\end{tabular}


Table I (Continued)

\begin{tabular}{|c|c|c|}
\hline $\begin{array}{l}\text { Concomitant } \\
\text { drug class }\end{array}$ & $\begin{array}{l}\text { Effect of concentration on } \\
\text { ATV or concomitant drug }\end{array}$ & Clinical comment \\
\hline Immunosuppressants & $\begin{array}{l}\text { 个cyclosporin, sirolimus, } \\
\text { tacrolimus }\end{array}$ & Close therapeutic concentration monitoring. \\
\hline Inhaled $\beta$-agonists & 个Salmeterol & $\begin{array}{l}\text { Increased risk of cardiovascular adverse events; coadministration } \\
\text { not recommended. }\end{array}$ \\
\hline Inhaled steroids & 个Fluticasone & $\begin{array}{l}\text { Increases risk of systemic steroid side effects. } \\
\text { Consider alternatives. }\end{array}$ \\
\hline Macrolide antibiotics & $\begin{array}{l}\uparrow \text { Atazanavir } \\
\uparrow \text { Clarithromycin }\end{array}$ & $\begin{array}{l}\text { Consider alternative therapies. If coadministered, dose reduction } \\
\text { of clarithromycin by } 50 \% \text { should be considered. }\end{array}$ \\
\hline Opioids & $\begin{array}{l}\text { TBuprenorphine, } \\
\text { norbuprenorphine }\end{array}$ & Close monitoring for effects of opioid toxicity. \\
\hline PDE5 inhibitors & $\begin{array}{l}\uparrow \text { Sildenafil, tadalafil, } \\
\text { vardenafil }\end{array}$ & $\begin{array}{l}\text { Coadministration has not been studied but may result in an } \\
\text { increase in PDE5 inhibitor-associated adverse events, including } \\
\text { hypotension, syncope, visual disturbances, and priapism. } \\
\text { See prescribing information for dosing recommendations. }\end{array}$ \\
\hline $\begin{array}{l}\text { Proton-pump } \\
\text { inhibitors (PPIs) }\end{array}$ & $\downarrow$ Atazanavir & $\begin{array}{l}\text { Coadministration with ATV in treatment-experienced patients } \\
\text { should not be used. If given to treatment-naïve patients, the PPI } \\
\text { dose should not exceed a dose comparable with omeprazole } \\
20 \mathrm{mg} \text { and should be taken } 12 \mathrm{~h} \text { prior to the ATV } 300 \mathrm{mg} \text { and } \\
\text { RTV } 100 \mathrm{mg} \text {. }\end{array}$ \\
\hline
\end{tabular}

Notes: Adapted from REYATAZ - Full Prescribing Information. Princeton, NJ: Bristol-Myers Squibb. Revised April 2010.12

Abbreviations: ECG, electrocardiography; HMG-CoA, 3-hydroxy-3-methylglutaryl-coenzyme A; INR, international normalized ratio; NNRTIs, nonnucleoside reverse transcriptase inhibitors; od, once daily; PDE5, phosphodiesterase type 5; PI, protease inhibitors.

because these two agents have been shown to lower the serum concentrations of ATV. In one trial, the Data Safety Monitoring Board recommended that participants be unblinded and switched to alternative therapy if they were randomized to a regimen that consisted of ATV + enteric-coated DDI + emtricitabine (FTC), as they exhibited an inferior virological response. ${ }^{24}$ Therefore, an alternative NRTI backbone other than DDI + FTC (or 3TC) should be considered if unboosted ATV is to be prescribed for a treatment-naïve patient.

The ALERT (Atazanavir or Lexiva with Ritonavir and Truvada) study was a 48-week, multicenter, open-label study in which $106 \mathrm{ARV}$-naïve patients were randomized to receive TFV/FTC + either fosamprenavir/RTV (FPV/r) or ATV/r. ${ }^{25}$ At baseline, the FPV/r or ATV/r arms were well matched for both viral load and CD4 counts with an HIV-1 RNA median of $4.9 \log ^{10}$ copies $/ \mathrm{mL}$ in both arms and a mean CD4 count of 176 and 205 cells $/ \mathrm{mm}^{3}$, respectively. At week 48, intentto-treat: $\mathrm{missing} /$ discontinuation $=$ failure analysis showed similar responses to $\mathrm{FPV} / \mathrm{r}$ and $\mathrm{ATV} / \mathrm{r}$ in terms of viral response (HIV-1 RNA $<50$ copies $/ \mathrm{mL}$ in $75 \%(40 / 53)$ vs $83 \%(44 / 53)(P=0.34)$ and immune reconstitution (mean $\mathrm{CD} 4{ }^{+}$count change from baseline: +170 and +183 cells $/ \mathrm{mm}^{3}$, $P=0.398)$. The investigators concluded that regimens of $\mathrm{TFV} / \mathrm{FTC}+$ either FPV/r or ATV/r showed similar virological and immunological efficacy over 48 weeks and similar lipid profiles. Fewer FPV/r-treated patients experienced treatmentrelated grade 2-4 adverse events during the course of the study, but this difference was mainly driven by ATV-related hyperbilirubinemia.

The CASTLE (Comparison of Atazanavir/Ritonavir in Naïve Subjects in Combination with TenofovirEmtricitabine Versus Lopinavir/Ritonavir in Combination with Tenofovir-Emtricitabine to Assess Safety and Efficacy) study has demonstrated that once-daily ATV/r with TDF and FTC is noninferior in achieving viral suppression to LPV/r at 96 weeks. ${ }^{26}$ This was an open-label, international study in which 883 ARV-naïve patients were randomly assigned to receive ATV/r (300/100 mg od) or LPV/r (400/100 mg bd) in combination with a fixed dose of TFV/FTC. The ATV/r arm was associated with significantly lower increases in total cholesterol, non-high-density lipoprotein cholesterol (non-HDL), and triglycerides at 96 weeks from baseline compared with LPV/r $(P<0.0001)$. In the study, $2 \%$ of patients in the ATV/r arm and $9 \%$ of patients in the LPV/r arm required initiation of lipid-lowering therapy. Patients in the ATV/r also had fewer gastrointestinal adverse events than those in the LPV/r arm, including diarrhea ( $2 \%$ and $12 \%$, respectively) and nausea (4\% and $8 \%$, respectively).

Induction-maintenance therapy is an HIV treatment strategy in which patients are prescribed an intense course 
of treatment for a short period of time (the induction phase), followed by a simplified long-term regimen (maintenance). Induction with $\mathrm{ATV} / \mathrm{r}$, abacavir (ABC), and 3TC has been shown to be both efficacious and tolerable in the 36-week ARIES (Atazanavir Ritonavir Induction/Simplification with Epzicom Study). ${ }^{27}$ Hyperbilirubinemia (13\%), diarrhea $(4 \%)$, nausea $(2 \%)$, and rash were the most common adverse events, and there were few discontinuations due to adverse events $(3 \%)$.

When used in combination with the NNRTI nevirapine (NVP), there was a substantial drop in the plasma ATV trough concentrations by almost half. ${ }^{28}$ Monitoring of trough levels and increases in the ATV dose may therefore be necessary in patients receiving NVP. The coadministration of FPV with unboosted ATV has also been shown to significantly decrease concentrations of ATV and is not a recommended combination. ${ }^{29}$

The AIDS Clinical Trials Group (ACTG) 5202 study was a blinded clinical trial in which 1857 treatment-naïve patients were randomized to begin one of the four different antiretroviral combinations. ${ }^{30}$ The study included four major comparisons: ABC/3TC versus TFV/FTC in patients on $\mathrm{ATV} / \mathrm{r}$; ABC/3TC versus TFV/FTC in patients receiving $\mathrm{EFV}$; ATV/r versus EFV in patients receiving $\mathrm{ABC} / 3 \mathrm{TC}$; and $\mathrm{ATV} / \mathrm{r}$ versus EFV in patients receiving TFV/FTC. Participants were also stratified into two groups: those with high ( $\geq 100,000$ copies/mL) and low $(<100,000$ copies/mL) viral loads. Primary endpoints were efficacy, safety, and tolerability. For patients on $\mathrm{ABC} / 3 \mathrm{TC}$, the probability of sustained suppression at 96 weeks was $83.4 \%$ in the ATV/r arm versus $85.3 \%$ in the EFV arm, with a hazard ratio (HR) for failure of 1.13 (95\% confidence interval [CI]: 0.82-1.56). For patients on TFV/FTC, the probability of sustained suppression was 89.0\% ATV/r arm versus 89.8\% EFV arm with an HR for failure of 1.01 (95\% CI: 0.70-1.46). There were significantly shorter times to adverse events and regimen changes in the ABC/3TC arm versus TFV/FTC when taken with EFV but not when taken with ATV/r. It was noted, however, that many of these were hypersensitivity reactions, and human leukocyte antigen screening was not standard practice at the time. Lipid profiles were more strongly affected by ABC/3TC than by TDF/FTC, and more affected by EFV than by ATV/r.

\section{ATV in ARV-experienced patients}

An early study looking at patients failing treatment compared ATV/saquinavir (SQV) with SQV/RTV (SQV/r) in combination with a two NRTI backbone. ${ }^{31}$ Two dosing arms of ATV/SQV were studied: 400/1200 and 600/1200 mg od.
In this study, the rationale for pairing ATV with SQV was based on the evidence of a booster effect of ATV on SQV via inhibition of the cytochrome P450 3A4 isoenzyme in the liver. ${ }^{32}$ The best virological response at 48 weeks was found in the ATV $400 \mathrm{mg}$ od group (41\%) over the ATV $600 \mathrm{mg}$ od (29\%) or SQV/r groups (35\%), and there were fewer adverse event discontinuations in the ATV/SQV groups than in those in the SQV/r arm. Salvage therapy refers to ARV regimens devised to reduce viral replication in treatment-experienced patients with virological failure on a prior regimen. This study was one of the first indications that ATV may have potential as a salvage regimen.

It has also been shown that ATV/r is as effective and well tolerated as LPV/r in treatment-experienced patients, with a more favorable impact on serum lipids. ${ }^{33}$ Patients $(n=358)$ who had failed two or more HAART regimens were randomized to receive ATV/r (300/100 mg od), ATV/SQV (400/1200 mg od), or LPV/r (400/100 mg bd), all paired with TFV once daily and one other NRTI. The patient group had high pre-existing levels of both NRTI and PI resistance mutations. The ATV/SQV arm was stopped at 24 weeks due to poor virological and immunological response. The intentionto-treat analysis at 96 weeks showed similar virological and immunological efficacy in the ATV/r and LPV/r arms. The results did also suggest, however, that ATV/r is of similar efficacy to LPV/r in antiretroviral (ARV)-experienced patients with fewer than four PI resistance mutations, but it was inferior when four or more PI resistance mutations were present. Grade 3-4 hyperbilirubinemia developed in 53\% of patients on ATV/r. This rate was higher than expected. Another study showed that patients who had failed on one PI regimen could be rescued with HAART containing unboosted ATV; however, greater viral suppression was seen in patients given $\mathrm{LPV} / \mathrm{r}^{34}$ This 48 -week, open-label study followed 290 patients randomized to receive a two NRTI backbone + either ATV or LPV/r. Both regimens demonstrated good antiviral activity, but LPV/r resulted in a significantly greater reduction in plasma HIV-RNA than unboosted ATV ( -2.02 vs $-1.59 \log ^{10}$ copies $\left./ \mathrm{mL}, P<0.001\right)$ at week 48. Immune reconstitution was also greater with LPV/r than with ATV (169 vs 112 cells/ $\mu \mathrm{L}$ ). The patients receiving ATV did, however, demonstrate a superior lipid profile and required less lipid lowering treatment.

The French prospective Nadis cohort study looked at 424 patients and assessed virological efficacy of an ATV/rcontaining regimen in patients with virological failure on an alternative regimen. They concluded that ATV/r-containing regimens may be useful in heavily ARV-experienced patients 
as long as the patients did not suffer previous LPV/r failures. ${ }^{35}$ This adds further weight to the concept of ATV/r as a valuable salvage option in heavily pretreated patients as long as a high number of PI mutations are not present. ${ }^{36}$

There was interest in double-boosted PI regimens for multiple treatment-experienced patients several years ago, but this interest has waned recently due to the introduction of new classes of ARVs such as integrase inhibitors, fusion inhibitors, CCR5 antagonists, new NNRTIs, and new PIs. ${ }^{37,38}$

Switching from a stable PI-based regimen that includes one thymidine analog to $\mathrm{ATV} / \mathrm{r}$ and either $\mathrm{ABC} / 3 \mathrm{TC}$ or TDF/ FTC has been shown to be effective in both maintaining viral suppression and reducing hyperlipidemia. ${ }^{39}$ Also, the AI424-067 study showed that a switch, either immediate or delayed, from another boosted or unboosted PI to unboosted ATV in patients with hyperlipidemia is associated with improvements in plasma lipid parameters without loss of virological suppression. ${ }^{40}$

Emerging data from a case series suggest that unboosted ATV in combination with the integrase inhibitor raltegravir (RAL) is tolerable and achieves good virological and immunological outcomes in treatment-experienced patients, but this is yet to be shown in randomized controlled trials. ${ }^{41}$

\section{Safety and tolerability}

Most studies report ATV to be generally well tolerated, and data from the SCOLTA (Surveillance Cohort Long-term Toxicity Antiretrovirals) project suggest that in unselected clinical settings, ATV-containing ARV regimens are both durable and safe. ${ }^{11}$ The most common side effect of ATV is hyperbilirubinemia. This effect is reversible on stopping ATV and rarely leads to discontinuation of the drug (1\%). Unconjugated bilirubin levels are normally seen to rise soon after the initiation of therapy, with a slight decline thereafter. The risk of hyperbilirubinemia is dose related and associated with RTV boosting. ${ }^{42}$ As previously described, the risk of hyperbilirubinemia is also associated with the UGT1A1* 28 genotype.

Elevation in transaminases has been observed in patients receiving ATV, but this effect does not correlate with hyperbilirubinemia. ${ }^{43}$ This risk is increased with underlying chronic liver disease. The AI424-007 study reported an association with underlying chronic viral hepatitis coinfection. Compared with monoinfected patients, there was a two-fold risk of significant transaminitis in patients coinfected with hepatitis $B$ while receiving ATV/DDI/D4T. ${ }^{18}$ This risk was seen to increase to four-fold in patients coinfected with chronic hepatitis $\mathrm{C}$. The manufacturer recommends that patients with moderate hepatic insufficiency (Child-Pugh class B) should have the ATV dosage reduced to $300 \mathrm{mg} /$ day. There are few data on the use of ATV in end-stage liver disease (ESLD). A small study of 15 patients with ESLD showed reasonable outcomes, with $10 / 15$ patients completing the 24 -week study with no significant changes in their markers of liver function, with the exception of unconjugated bilirubin. Further data are needed in this patient group, however. ${ }^{44}$

A small study of 10 patients has shown an association of concurrent ATV and LPV/r administration with cardiac conduction abnormalities. ${ }^{45}$ Prolonged PR and QRS intervals occurred in the majority of patients, and two patients developed new-onset arrhythmias (bundle branch block, atrioventricular block), resulting in premature termination of the study. It should be noted, however, that this was a very small study group, and the coadministration of ATV with LPV/r is not a component of common HAART regimens.

\section{Patient-focused perspectives}

When compared with other PIs, the favorable lipid profile of ATV has been demonstrated in a number of studies. This raises questions about whether it would be a suitable alternative for those patients who are stable on a PI-based regimen with hyperlipidemia. In 2009, Sension et al set out to compare the change in fasting LDL cholesterol from baseline to week 12 between patients with hyperlipidemia $(\mathrm{n}=246)$ who switched to an ATV-containing regimen and those continuing on a comparator PI regimen. ${ }^{40}$ They found that a switch (either immediate or delayed) from a boosted or unboosted PI to unboosted ATV was associated with improvements in plasma lipid parameters without loss of virological suppression, with patients in the immediate switch group demonstrating a $15 \%$ reduction in LDL cholesterol at week 12. It should be noted, however, that rates of viral rebound in this study were $15 \%$ and $10 \%$ in the immediate and delayed switch groups, respectively. This is likely to reflect the fact that many of the patients in the study group had previously received suboptimal dual NRTI therapy and, in this situation, ATV/r would have been preferable over unboosted ATV.

The SWAN (Switch to Another Protease Inhibitor) study was a 48-week, open-label trial involving HIV-positive patients receiving PI-based regimens with stable virological suppression with or without RTV boosting. ${ }^{46}$ Patients $(\mathrm{n}=419)$ were randomized 2:1 to switch to ATV (400 mg od) or, if they were receiving TFV, to ATV/r (300/100 mg od), or to continue to receive their existing PI. They concluded that in patients with virological suppression who were receiving 
other PIs, a switch to a once-daily regimen containing ATV provides better maintenance of virological suppression (7\% in the switch arm vs $16 \%$ in the comparator PI regimen arm), a comparable safety profile, and improved lipid parameters, including total cholesterol, fasting triglyceride, and non-HDL cholesterol.

The effect of ATV on glucose tolerance has also been compared with other PI-based regimens. One small study showed that switching from LPV/r to ATV/r results in significantly increased glucose uptake by muscle, decreased abdominal visceral adipose tissue, improved lipid parameters, and decreased fasting glucose over 6 months. ${ }^{47}$ Another study evaluated the 24-week effect on glucose tolerance of switching from an alternative PI-based regimen to an unboosted ATV-based regimen in highly pretreated HIV-1 patients with metabolic alterations. ${ }^{48}$ This was a prospective, open-label, single-center, 24-week pilot study in which 21 subjects underwent an oral glucose tolerance test at baseline and after 24 weeks of unboosted ATV. Various metabolic and lipid parameters were also measured, including insulin sensitivity, $\beta$-cell responsiveness, fasting glucose, insulin, $\mathrm{C}$-peptide, triglycerides, total cholesterol, and HDL- and LDL-cholesterol. After 24 weeks of unboosted ATV, the 120 min glucose level was significantly lower than the one measured at baseline, and there were no statistically significant differences in the insulin concentration profile. The results showed that switching from a PI-based regimen to an unboosted ATVbased regimen leads to a significant improvement in glucose tolerance in highly pretreated HIV-1-infected subjects with metabolic alterations. Improvement in the lipid profile of these patients was demonstrated again in the ATV arm, and there was no significant difference in HIV-1 RNA or CD4 count.

ATV is less likely to induce lipodystrophy than other PIs. One study showed that use of ATV for 48 weeks neither resulted in abnormal fat redistribution in ARV-naïve patients nor induced other metabolic disturbances commonly associated with HIV-related lipodystrophy. ${ }^{49}$ A subsequent 96-week, open-label, randomized study assessed changes in body composition in treatment-naïve patients who were treated with either ATV or ATV/r in combination with D4T/3TC. ${ }^{50}$ Both treatment groups had similar increases in trunk fat, but patients treated with ATV/r had a significantly lower incidence of lipoatrophy. The REAL (Research into Atazanavir in Lipodystrophy) study was a multicenter, openlabel, randomized, prospective study in which 201 patients with a waist circumference $>90 \mathrm{~cm}$ and a viral load $<400$ copies/mL were randomized (2:1) to ATV/r versus continuing a comparator-boosted PI regimen. ${ }^{51}$ The 48-week analysis showed that patients in the switch group showed no significant change in body composition but maintained viral suppression. Significant improvements in lipid profiles were seen in the ATV/r arm. Further long-term studies are needed to assess the true effect of ATV on lipodystrophy.

\section{Simplification}

The issue of long-term adverse events from multiple ARVs and the lifestyle implications of strict adherence to multidrug regimens have led to the development of strategies aimed at simplifying therapy. ATV's once-daily dosing and good adverse event profile make it a good candidate for inclusion in simplified regimens. A randomized, open-label, noninferiority study of $515 \mathrm{ARV}$-naïve patients has shown that ATV in combination with $\mathrm{ABC} / 3 \mathrm{TC}$, and without RTV boosting, is a potent and well-tolerated regimen in patients who have achieved initial suppression on an induction regimen. ${ }^{52}$ These patients all received an induction regimen of $\mathrm{ABC}$, 3TC, and ATV/r for 36 weeks, before being randomized to continue or discontinue RTV. Noninferiority of this simplified regimen was demonstrated at week 84 , with $181 / 210$ patients maintaining a viral load of $<50$ copies in the unboosted arm versus 169/209 in the RTV-boosted arm. The SLOAT (Simplification Lopinavir to Atazanavir) study monitored 66 patients receiving LPV/r-based regimens. ${ }^{53}$ All patients had undetectable HIV plasma RNA for $>24$ weeks and were randomized to continue on the same therapy or switch to either ATV (400 mg od) or ATV/r (300/100 mg od) if receiving TFV. There was no significant difference between the two groups in rates of virological failures at 48 weeks. A significant reduction was seen in median total cholesterol $(-19 \mathrm{mg} / \mathrm{dL})$ and triglycerides $(-80 \mathrm{mg} / \mathrm{dL})$ in the ATV switch group, whereas no significant changes occurred in the control LPV/r arm. The reduction in total cholesterol and triglycerides was greater in patients switched to ATV without RTV boosting. These two studies show that ATV may have a valuable role in treatment simplification strategies; however, there is a need for longer-term data.

\section{Conclusion}

ATV-based antiretroviral regimens offer simple, safe, and effective strategies for both treatment-naïve and treatmentexperienced patients. The development of drugs such as ATV has resulted in significant improvements in health and quality of life for HIV-1-infected individuals toward those of people without retroviral infection. Although further work is needed to determine the role of this drug in some specific 
patient groups, and care must be employed when prescribing other medications with respect to drug interactions, the potential that ATV has shown in studies focused on salvage, simplification, and induction-maintenance strategies is encouraging.

\section{Disclosure}

The authors report no conflicts of interest in this work.

\section{References}

1. FDA notifications. Reyataz is approved for HIV treatment. AIDS Alert. 2003;18(9):119-120.

2. von Hentig N, Babacan E, Lennemann T, et al. The steady-state pharmacokinetics of atazanavir/ritonavir in HIV-1-infected adult outpatients is not affected by gender-related co-factors. J Antimicrob Chemother. 2008;62(3):579-582.

3. Anderson PL, Aquilante CL, Gardner EM, et al. Atazanavir pharmacokinetics in genetically determined CYP3A5 expressors versus nonexpressors. J Antimicrob Chemother. 2009;64(5):1071-1079.

4. Müller AC, Kanfer I. An efficient HPLC method for the quantitative determination of atazanavir in human plasma suitable for bioequivalence and pharmacokinetic studies in healthy human subjects. J Pharm Biomed Anal. 2010;53(1):113-118.

5. Best BM, Letendre SL, Brigid E, et al. Low atazanavir concentrations in cerebrospinal fluid. AIDS. 2009;23(1):83-87.

6. Taburet AM, Piketty C, Chazallon C, et al. Interactions between atazanavir-ritonavir and tenofovir in heavily pretreated human immunodeficiency virus-infected patients. Antimicrob Agents Chemother. 2004;48(6):2091-2096.

7. Klein CE, Chiu YL, Cai Y, et al. Effects of acid-reducing agents on the pharmacokinetics of lopinavir/ritonavir and ritonavir-boosted atazanavir J Clin Pharmacol. 2008;48(5):553-562.

8. Zhu L, Persson A, Mahnke L, et al. Effect of low-dose omeprazole (20 mg daily) on the pharmacokinetics of multiple-dose atazanavir with ritonavir in healthy subjects. J Clin Pharmacol. 2010 May. Epub ahead of print.

9. Krishna G, Moton A, Ma L, Martinho M, Seiberling M, McLeod J. Effects of oral posaconazole on the pharmacokinetics of atazanavir alone and with ritonavir or with efavirenz in healthy adult volunteers. J Acquir Immune Defic Syndr. 2009;51(4):437-444.

10. Havlir DV, O'Marro SD. Atazanavir: new option for treatment of HIV infection. Clin Infect Dis. 2004;38(11):1599-1604.

11. Giuntini R, Martinelli C, Ricci E, et al. Efficacy and safety of boosted and unboosted atazanavir-containing antiretroviral regimens in real life: results from a multicentre cohort study. HIV Med. 2010;11(1): 40-45.

12. REYATAZ - Full Prescribing Information. Princeton, NJ: Bristol-Myers Squibb. Revised 2010 Apr.

13. Lambert-Niclot S, Machouf N, Peytavin G, et al. Pharmacokinetics, protein-binding-adjusted inhibitory quotients for atazanavir/ritonavir 300/100 mg in treatment-naïve HIV-infected patients. HIV Med. 2010; 11(10):666-669.

14. Colonno R, Rose R, McLaren C, Thiry A, Parkin N, Friborg J. Identification of I50L as the signature atazanavir (ATV)-resistance mutation in treatment-naive HIV-1-infected patients receiving ATV-containing regimens. J Infect Dis. 2004;189(10):1802-1810.

15. Sista P, Wasikowski B, Lecocq P, Pattery T, Bacheler L. The HIV-1 protease resistance mutation $\mathrm{I} 50 \mathrm{~L}$ is associated with resistance to atazanavir and susceptibility to other protease inhibitors in multiple mutational contexts. J Clin Virol. 2008;42(4):405-408.

16. de Mendoza C, Garrido C, Corral A, et al. Changing rates and patterns of drug resistance mutations in antiretroviral-experienced HIV-infected patients. AIDS Res Hum Retroviruses. 2007;23(7):879-885.
17. Colonno RJ, Thiry A, Limoli K, Parkin N. Activities of atazanavir (BMS-232632) against a large panel of human immunodeficiency virus type 1 clinical isolates resistant to one or more approved protease inhibitors. Antimicrob Agents Chemother. 2003;47(4):1324-1333.

18. Sanne I, Piliero P, Squires K, Thiry A, Schnittman S; AI424-007 Clinical Trial Group. Results of a phase 2 clinical trial at 48 weeks (AI424-007): a dose-ranging, safety, and efficacy comparative trial of atazanavir at three doses in combination with didanosine and stavudine in antiretroviral-naive subjects. J Acquir Immune Defic Syndr. 2003; 32(1):18-29.

19. Wood R, Phanuphak P, Cahn P, et al. Long-term efficacy and safety of atazanavir with stavudine and lamivudine in patients previously treated with nelfinavir or atazanavir. J Acquir Immune Defic Syndr. 2004;36(2): 684-692.

20. Squires K, Lazzarin A, Gatell JM, et al. Comparison of once-daily atazanavir with efavirenz, each in combination with fixed-dose zidovudine and lamivudine, as initial therapy for patients infected with HIV. J Acquir Immune Defic Syndr. 2004;36(5):1011-1019.

21. Malan DR, Krantz E, David N, et al. 96-week efficacy and safety of atazanavir, with and without ritonavir, in a HAART regimen in treatment-naive patients. $J$ Int Assoc Physicians AIDS Care (Chic). 2010;9(1):34-42.

22. Malan DR, Krantz E, David N, Wirtz V, Hammond J, McGrath D; 089 Study Group. Efficacy and safety of atazanavir, with or without ritonavir, as part of once-daily highly active antiretroviral therapy regimens in antiretroviral-naive patients. J Acquir Immune Defic Syndr. 2008; 47(2):161-167.

23. Panel on Antiretroviral Guidelines for Adults and Adolescents. Guidelines for the Use of Antiretroviral Agents in HIV-1-Infected Adults and Adolescents. Department of Health and Human Services; 2009:1-161. Available from: http://www.aidsinfo.nih.gov/ContentFiles/ Adultand AdolescentGL.pdf. Accessed December 20, 2010.

24. Campbell T, Smeaton L, de Grutolla V, et al. PEARLS (ACTG A5175): a multinational study of didanosine-EC, emtricitabine and atazanavir vs. co-formulated zidovudine/lamivudine and efavirenz for initial treatment of HIV-1 infection. XVII International AIDS Conference; 2008 Aug 3-8; Mexico City.

25. Smith KY, Weinberg WG, DeJesus E, et al. Fosamprenavir or atazanavir once daily boosted with ritonavir $100 \mathrm{mg}$, plus tenofovir/emtricitabine, for the initial treatment of HIV infection: 48-week results of ALERT. AIDS Res Ther. 2008;5:5.

26. Molina JM, Andrade-Villanueva J, Echevarria J, et al. Once-daily atazanavir/ritonavir compared with twice-daily lopinavir/ritonavir, each in combination with tenofovir and emtricitabine, for management of antiretroviral-naive HIV-1-infected patients: 96-week efficacy and safety results of the CASTLE study. J Acquir Immune Defic Syndr. 2010;53(3):323-332.

27. Squires KE, Young B, DeJesus E, et al. Safety and efficacy of a 36-week induction regimen of abacavir/lamivudine and ritonavir-boosted atazanavir in HIV-infected patients. HIV Clin Trials. 2010;11(2):69-79.

28. Moltó J, Deig E, Valle M, et al. Effect of nevirapine on the steady-state trough concentrations of atazanavir in HIV-infected patients receiving atazanavir/ritonavir. Ther Drug Monit. 2010;32(1):93-96.

29. McRae M, Clay PG, Anderson PL, Glaros AG. Pharmacokinetics of concurrent administration of fosamprenavir and atazanavir without ritonavir in human immunodeficiency virus-negative subjects. Pharmacotherapy. 2009;29(8):937-942.

30. Daar E, Tierney C, Fischl M, et al. ACTG 5202: final results of $\mathrm{ABC} / 3 \mathrm{TC}$ or TDF/FTC with either EFV or ATV/r in treatment-naive HIV-infected patients. 17th Conference on Retroviral and Opportunistic Infection; 2010; San Francisco.

31. Haas DW, Zala C, Schrader S, et al. Therapy with atazanavir plus saquinavir in patients failing highly active antiretroviral therapy: a randomized comparative pilot trial. AIDS. 2003;17(9):1339-1349.

32. Boffito M, Kurowski M, Kruse G, et al. Atazanavir enhances saquinavir hard-gel concentrations in a ritonavir-boosted once-daily regimen. AIDS. 2004;18(9):1291-1297. 
33. Johnson M, Grinsztejn B, Rodriguez C, et al. Atazanavir plus ritonavir or saquinavir, and lopinavir/ritonavir in patients experiencing multiple virological failures. AIDS. 2005;19(7):685-694.

34. Cohen C, Nieto-Cisneros L, Zala C, et al. Comparison of atazanavir with lopinavir/ritonavir in patients with prior protease inhibitor failure: a randomized multinational trial. Curr Med Res Opin. 2005;21(10): 1683-1692.

35. Cuzin L, Flandre P, Pugliese P, et al. Atazanavir in patients with persistent viral replication despite HAART: results from the French prospective NADIS cohort. HIV Clin Trials. 2008;9(3):147-151.

36. de Mendoza C, Valer L, Ribera E, et al. Performance of six different ritonavir-boosted protease inhibitor-based regimens in heavily antiretroviral-experienced HIV-infected patients. HIV Clin Trials. 2006;7(4):163-171.

37. Ribera E, Azuaje C, Lopez RM, et al. Atazanavir and lopinavir/ritonavir: pharmacokinetics, safety and efficacy of a promising double-boosted protease inhibitor regimen. AIDS. 2006;20(8):1131-1139.

38. Manosuthi W, Sungkanuparph S, Ruxrungtham K, et al. Plasma levels, safety, and 60-week efficacy of a once-daily double-boosted protease inhibitor regimen of atazanavir, saquinavir, and ritonavir. J Acquir Immune Defic Syndr. 2008;47(1):127-129.

39. Calza L, Manfredi R, Colangeli V, et al. Efficacy and safety of atazanavirritonavir plus abacavir-lamivudine or tenofovir-emtricitabine in patients with hyperlipidaemia switched from a stable protease inhibitor-based regimen including one thymidine analogue. AIDS Patient Care STDS. 2009;23(9):691-697.

40. Sension M, Andrade Neto JL, Grinsztejn B, et al. Improvement in lipid profiles in antiretroviral-experienced HIV-positive patients with hyperlipidemia after a switch to unboosted atazanavir. J Acquir Immune Defic Syndr. 2009;51(2):153-162.

41. Gupta S, Lataillade M, Farber S, Kozal MJ. Raltegravir with unboosted atazanavir $300 \mathrm{mg}$ twice daily in antiretroviral treatment-experienced participants. J Int Assoc Physicians AIDS Care (Chic). 2009;8(2): 87-92.

42. Rodríguez Nóvoa S, Barreiro P, Rendón A, et al. Plasma levels of atazanavir and the risk of hyperbilirubinemia are predicted by the $3435 \mathrm{C}->\mathrm{T}$ polymorphism at the multidrug resistance gene 1 . Clin Infect Dis. 2006;42(2):291-295.

43. Rivas P, Morello J, Garrido C, Rodríguez-Nóvoa S, Soriano V. Role of atazanavir in the treatment of HIV infection. Ther Clin Risk Manag. 2009;5(1):99-116.
44. Guaraldi G, Cocchi S, Motta A, et al. Efficacy and safety of atazanavir in patients with end-stage liver disease. Infection. 2009;37(3): 250-255.

45. Rathbun CR, Liedtke MD, Blevins SM, et al. Electrocardiogram abnormalities with atazanavir and lopinavir/ritonavir. HIV Clin Trials. 2009;10(5):328-336.

46. Gatell J, Salmon-Ceron D, Lazzarin A, et al. Efficacy and safety of atazanavir-based highly active antiretroviral therapy in patients with virologic suppression switched from a stable, boosted or unboosted protease inhibitor treatment regimen: the SWAN study (AI424-097) 48-week results. Clin Infect Dis. 2007;44(11):1484-1492.

47. Stanley TL, Joy T, Hadigan CM, et al. Effects of switching from lopinavir/ritonavir to atazanavir/ritonavir on muscle glucose uptake and visceral fat in HIV-infected patients. AIDS. 2009;23(11):1349-1357.

48. Guffanti M, Caumo A, Galli L, et al. Switching to unboosted atazanavir improves glucose tolerance in highly pretreated HIV-1 infected subjects. Eur J Endocrinol. 2007;156(4):503-509.

49. Jemsek JG, Arathoon E, Arlotti M, et al. Body fat and other metabolic effects of atazanavir and efavirenz, each administered in combination with zidovudine plus lamivudine, in antiretroviral-naive HIV-infected patients. Clin Infect Dis. 2006;42(2):273-280.

50. McComsey G, Rightmire A, Wirtz V, Yang R, Mathew M, McGrath D. Changes in body composition with ritonavir-boosted and unboosted atazanavir treatment in combination with Lamivudine and Stavudine: a 96-week randomized, controlled study. Clin Infect Dis. 2009;48(9):1323-1326.

51. Moyle G, Girard PM, Andrade J, et al. Continuation of BID boosted PI vs switch to once-daily ATV/RTV for the management of lipodystrophy: 48 week primary analysis of the 96 week multicenter, open-label, randomized, prospective ReAL study. XVII International AIDS Conference; 2008 Aug 3-8; Mexico City.

52. Squires KE, Young B, DeJesus E, et al. Similar efficacy and tolerability of atazanavir compared with atazanavir/ritonavir, each with abacavir/ lamivudine after initial suppression with abacavir/lamivudine plus ritonavir-boosted atazanavir in HIV-infected patients. AIDS. 2010;24(13): 2019-2027.

53. Soriano V, García-Gasco P, Vispo E, et al. Efficacy and safety of replacing lopinavir with atazanavir in HIV-infected patients with undetectable plasma viraemia: final results of the SLOAT trial. J Antimicrob Chemother. 2008;61(1):200-205.
Virus Adaptation and Treatment

\section{Publish your work in this journal}

Virus Adaptation and Treatment is an international, peer-reviewed open access journal focusing on the study of virology, viral adaptation and the development and use of antiviral drugs and vaccines to achieve improved outcomes in infection control and treatment. The journal welcomes original research, basic science, clinical \& epidemiological

\section{Dovepress}

studies, reviews \& evaluations, expert opinion and commentary, case reports and extended reports. The manuscript management system is completely online and includes a very quick and fair peer-review system, which is all easy to use. Visit http://www.dovepress.com/ testimonials.php to read real quotes from published authors. 